\title{
Thickness based Characterization of Ultrasound Placenta Images using Regression Analysis
}

\author{
G. Malathi \\ Affiliated to Anna University \\ Velammal Engineering College \\ Chennai 66, India
}

\author{
Dr. V. Shanthi \\ Affiliated to Anna University \\ St. Joseph Engineering College \\ Chennai 96, India
}

\begin{abstract}
In the medical domain, one of the major challenges faced by the medical experts is the extraction of critical information for medical diagnosis. Specialized tools are necessary to assist the experts in diagnosing the diseases. Information retrieval is difficult in the case of ultrasound medical images due to its low resolution making diagnosis difficult. Gestational diabetes is a form of diabetes, which affects pregnant women. It is believed that the hormones produced during pregnancy reduce a woman's receptivity to insulin, leading to high blood sugar levels. The duration of departures from normogycemia in maternal diabetes is the critical factor. The earlier detection of GDM occurs, the lesser the influence on placental development, which indirectly accounts for fetal growth and metabolism. This pilot study involves the feasibility for classifying the ultrasound images of placenta with complicating diabetes based on placenta thickness using statistical textural features
\end{abstract}

\section{Keywords:}

Placenta, Image Pre processing, Regression Analysis, Textural Features. Classification, neural networks, Gestational Diabetes Mellitus, thickness equation

\section{INTRODUCTION}

Diabetes is still poorly controlled in India owing to delays in early detection and proper treatment, says a study conducted by the International Diabetes Management Practices Study (IDMPS). IDMPS is a five-year survey involving 1755 Indian participants. With an estimated figure of 40.9 million diabetics, India is the diabetes capital of the world, followed by China and the United States. The World Health Organization (WHO) estimates the number of diabetics to exceed 350 million by 2030 . Governments and other healthcare providers around the world are investing in health education, diagnosis and treatments for this chronic, debilitating but controllable disease [1]. Maternal diabetes mellitus complicates pregnancy with combinations of growth-promoting and growth-restricting forces which may alter the normal growth trajectories of both the fetus and placenta. The human placenta is a focal, disk-like thickening of the membranous sac that is achieved by splitting the membranes into two separate sheets, the chorionic plate and the basal plate. Maternal diabetes is a condition that can be associated with large placentas. Large placentas, however, should raise the suspicion for a maternal diabetic state[2]. The study in [3], demonstrates that there is change in shape in one placenta from diabetic group. Weight central thicknesss and diameter were significantly greater in diabetic group as compared to normal and hypertensive group. Placenta is an essential organ for exchange of nutrients and metabolites between mother and fetus [4]. Placentas less than $2.5 \mathrm{~cm}$ thick are associated with intrauterine growth retardation of the fetus.[5] Placentas more than $4 \mathrm{~cm}$ thick have an association with maternal diabetes mellitus, fetal hydrops and intrauterine fetal infections [6].

The task of classifying ultrasonic images of the placenta according with the gradation proposed by Grannum is attempted in [7]. The ability of a decision tree classifier to discriminate different textures with three sets of textural features was tested. The performance of the classifier using textural features corresponding to co-ocurrence matrices, Law's operators and neighborhood gray-tone difference matrices (NGDTM) was firstly assessed. In [8] ,the feasibility for detecting anomalies in placental growth due to the implications of gestational diabetics by considering the stereo image mapping based on wavelet analysis for $2 \mathrm{D}$ reconstruction was studied. With the image matching strategy the corresponding points between left image and right image in stereo image pair can be obtained and matched. The shape of the placenta was reconstructed using the Back Propagation Neural Network. The research used wavelet-based methods to extract features from the ultrasonic images of placenta. The Euclidean Distance Classifier was used to classify the ultrasonic images of placenta as normal placenta and abnormal placenta with the implications of gestational diabetes mellitus.

In [9] , the classification of scans of the placenta according with Grannum grading is attempted and used feature selection for determining the relevant textural features that were extracted from the scans. Three different sets of textural features, namely co-occurrence matrices, Laws masks and neighborhood gray-tone difference matrices (NGTDM) were used. The strategy used for classification was the k-Nearest Neighbor algorithm using leave-one-out crossvalidation. In [10], the region-growing algorithm was to extract features from the ultrasonic images of placenta and employed $\mathrm{K}$ nearest neighbor technique for classification of ultrasonic images of placenta using region growing segmentation method. The cases were classified into four groups namely 
- Group1: These groups consisted of 121 normal placentas not affected by any disease.

- Group2: This group consisted of 10 placentas affected by hypertension.

- Group3: This group consisted of 10 placentas affected by placenta previa.

- Group4: These groups consisted of 10 placentas affected by gestational diabetics mellitus.

The geometrical features which include shape, perimeter, area of the placentas were included in this study.

Tools for the statistical analysis of placenta shapes using a random sample of placenta images was presented in [11], by noting the key features of the shape like the position of the Umbilical Cord Insertion Point relative to the outer and inner perimeters, the thickness of the inter perimeter region, shape of the perimeter boundaries like convexity, roundness to predict features of the new born with presence of some disease or abnormality. The relation between Foetal Placenal Ratio and placenta shape by building a regression model explaining FPR as a function of shape and estimating the posterior distribution of FPR given shape using Kernel based methods.

In [16], the authors have made an attempt to classify the placenta based on the intensity level of histogram of theultrasound images of placenta. The image histogram is used to classify the ultrasound images of placenta into normal and abnormal placenta using $\mathrm{k}$ nearest neighbor classifier. It is further used to analyze the complications of gestational diabetes mellitus on the growth of placenta. The statistical moments obtained above were broadly classified into two groups as normal placenta and abnormal placenta. The abnormal placenta images were further classified into specific conditions of placenta during the gestational period. The training set includes the data for classification for each specific category of ultrasound placenta images. For every new input, the textural features for mean, contrast, correlation and entropy are obtained. The new input is placed in the class that contains the most items which is close to the specific class of image. Technique identifies the implications of diabetes mellitus on the growth of the placenta.

\section{IMAGE PRE-PROCESSING}

The ultrasound images of placenta obtained is subjected to histogram equalization to enhance the contrast of the input image. The ultrasound placenta images is then reduced to $64 X 64$ pixels and stored. The reduced image is used in measuring the placentae thickness, area and perimeter using the crown - rump length and biparietal diameter.

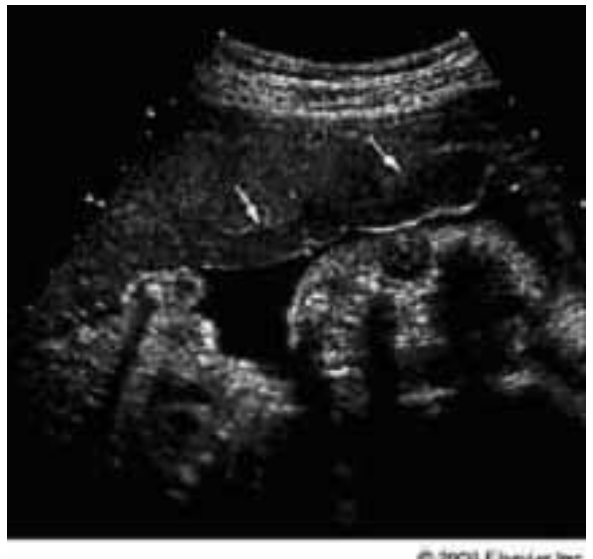

Fig. I: Grayscale sonogram revealing a subchorionic hematoma

\section{MEASURING PLACENTA THICKNESS}

Ultrasonographic placental diameter and thickness measurements appears to be of prognostic value in identifying the subsequent occurrence of fetal growth retardation. The study aimed at assessing placental diameter, placental thickness measured by ultrasound scan and estimated placental volume [12] and classify the ultrasound placenta images as normal and abnormal placenta complicated with gestational diabetes mellitus. The study included the following criteria 1.Known last menstrual period (LMP) 2.Viable singleton cyesis 3.Nil history of diabetes mellitus or other metabolic diseases 4.Nil history of previous adverse fetal outcome 5.Nil history of intrauterine growth retardation 6.Nil co-existing uterine or adenexal mass 7.Nil placental mass or anomaly 8.Nil fetal mass or anomaly 9.Placenta can be distinguished from the myometrium 10.Nil history of immune or non-immune hydrops 11.Nil hydroamnios 12 . Nil pregnancy induced hypertension (PIH) The foetus was observed for gross anatomical defects and the gestational age estimated using crown - rump length (CRL) and biparietal diameter (BPD) in the first trimester, (BPD) and femur length (FL) in the second trimester and BPD, FL and abdominal circumference (AC) in the third trimester. The placenta was localized in longitudinal section and its anteroposterior thickness measured at the level of insertion of the umbilical cord. Correlation and regression analysis was used to establish the relationship between placental thickness and gestational age. Regression analysis yielded the following linear equations of relationship between gestational age (y) in weeks and placental thickness (PT) in mm: [13].

In the first trimester

$\mathrm{y}=0.374(\mathrm{PT})+5.568(\mathrm{r}=0.729)$

In the second trimester

$\mathrm{y}=0.4323(\mathrm{PT})+9.2742(\mathrm{r}=0.671)$ 
In the third trimester

$\mathrm{y}=0.3106(P T)+21.832(\mathrm{r}=0.557)$

In the combined trimester

$\mathrm{y}=0.7347(\mathrm{PT})+3.8881(\mathrm{r}=0.872)$

(Eq 4)

Table I.: Regression coefficient in the logistic model for predicting low birthweight from placental parameters at 36 weeks of gestation.

\begin{tabular}{|c|c|c|c|c|c|c|}
\hline \multicolumn{7}{|c|}{ Regression Coefficient } \\
\hline Variables & $B$ & S-E ( $(3)$ & Wald stat & O.R. & $95 \%$ CI & Ref \\
\hline Constant & -8.8845 & 3.44 & 6.66 & & & {$[12]$} \\
\hline $\begin{array}{c}\text { Placental } \\
\text { diameter }\end{array}$ & 0.3994 & 0.1976 & 4.08 & 1.49 & $\begin{array}{c}1.01- \\
2-20\end{array}$ & {$[12]$} \\
\hline $\begin{array}{l}\text { Placental } \\
\text { thickness }\end{array}$ & 1.2482 & 0.4641 & 7.23 & 3.48 & $\begin{array}{c}1.40- \\
{[12]}\end{array}$ \\
\hline
\end{tabular}

Overall prediction rate $=88.6 \%$.

Table II: Distribution of placental thickness according to gestational age

\begin{tabular}{|c|c|c|c|}
\hline $\begin{array}{c}\text { Gestationa } \\
\text { Age (wks) }\end{array}$ & $\begin{array}{c}\text { Number } \\
\text { of cases }\end{array}$ & $\begin{array}{l}\text { Placental } \\
\text { thickness mm }\end{array}$ & Reference \\
\hline 7 & 7 & $9.6+1.9$ & {$[13]$} \\
\hline 8 & 3 & $9.0+1.0$ & {$[13]$} \\
\hline 9 & 17 & $10.9+1.7$ & {$[13]$} \\
\hline 10 & 9 & $10.0+1.2$ & {$[13]$} \\
\hline 11 & 6 & $11.0+0.9$ & {$[13]$} \\
\hline 12 & 13 & $15.3+3.1$ & {$[13]$} \\
\hline 13 & 9 & $18.0+3.0$ & {$[13]$} \\
\hline
\end{tabular}

Mean placental thickness $=12.5+3.7$
Table III: Pearson's correlation values between placental thickness and gestational age

\begin{tabular}{|c|c|c|c|c|c|}
\hline & \multicolumn{5}{|c|}{ Trimesters } \\
\hline & First & Second & Third & $\begin{array}{c}\text { Combi- } \\
\text { ned }\end{array}$ & Ref \\
\hline \begin{tabular}{|c|} 
Pearsons \\
Correlation \\
Coefficien \\
$(\mathrm{r})$ \\
\end{tabular} & $\mathrm{r}=0.729$ & $r=0.671$ & $r=0.557$ & $\begin{array}{c}r= \\
0.872\end{array}$ & [13] \\
\hline P - values & $\mathrm{p}<0.01$ & $\mathrm{p}<0.01$ & $\mathrm{p}<0.01$ & $\mathrm{p}<0.0$ & [13] \\
\hline $\begin{array}{l}\text { Number } \\
\text { of } \\
\text { measure- } \\
\text { ment (n) }\end{array}$ & $\mathrm{n}=64$ & $\mathrm{n}=237$ & $\mathrm{n}=429$ & $n=730$ & [13] \\
\hline
\end{tabular}

Placental thickness of less than $2.5 \mathrm{~cm}$ is associated with intrauterine growth retardation (Kunlmann and Warsof, 1996) while thick placentas are associated with maternal diabetes mellitus, foetal hydrops and intrauterine foetal infections.[14]

Table IV. Correlation between placental thickness and the growth parameters; biparietal diameter (BPD) and abdominal circumference (AC).

\begin{tabular}{|c|c|c|c|}
\hline Pregnancy & BPD & AC & Reference \\
\hline $\begin{array}{c}\text { Second } \\
\text { trimester }\end{array}$ & $\mathrm{r}=0.626$ & $\mathrm{r}=0.626$ & {$[14]$} \\
\hline$(\mathrm{n}=244)$ & $\mathrm{p}=0.000$ & $\mathrm{p}=0.000$ & {$[14]$} \\
\hline $\begin{array}{c}\text { Third } \\
\text { trimester }\end{array}$ & $\mathrm{r}=0.522$ & $\mathrm{r}=0.523$ & {$[14]$} \\
\hline
\end{tabular}

The placental thickness data were analyzed for mean, standard deviation, $95 \%$ confidence interval, and $2.5^{\text {th }}, 5^{\text {th }}$, $50^{\text {th }}, 95^{\text {th }}$, and $97.5^{\text {th }}$ percentile for each week of gestational age. The best-fit mathematical model was derived by regression analysis. Regression analysis yielded the following linear equation of the relationship: [15] 
$\mathrm{PT}=\mathrm{GA} \times 1.4-5.6(\mathrm{r}=0.82)$.

Where,

PT=placenta Thickness (in mm)

$\mathrm{GA}=$ Gestational Age (in weeks)

\section{TEXTURAL FEATURES}

Texture based features: area, perimeter and thickness of the placenta. The crown rump length (CRL) and biparietal diameter (BPD) are obtained from the ultrasound image of the placenta. The shape features were found to correlate with a subjective assesment of the texture. Regarding the size (weight, diameter, central thickness) a highly significant increase in weight (22\%), diameter (33\%) and ventral thickness (85\%) [3] was found in placentae of diabetic mothers when compared with normal placentae.

A. Shape of Placentae: The placentae were roughly oval or rounded in shape in all groups except the placenta complicatied by gestational diabetes mellitus

B. Diameter of placentae: Mean diameter of placentae significantly increase in ultrasound placenta image complicated by diabetes

C. Central Thickness:Mean central thickness was found to increase significantly in placenta complicated by gestational diabetes mellitus.

\section{CLASSIFICATION}

The ultrasound placenta images are then classified into normal placenta and placenta complicated by gestational diabetes. Initially the ultrasound placenta images are marked as normal or placenta complicated by GDM by the experts in the medical field. This is used to confirm the classification accuracy. The above tabulated values shows that there is a significant increase in thickness, area and biparietal diameter in the case of placentae complicated by diabetes and also in case of intra uterine growth retardation which can be suspected as a cause of GDM.

\section{CONCLUSION}

The earlier screening for Diabetes Milletus in pregnancy influence on placental development, which indirectly accounts for fetal growth and metabolism. This study attempted to find the feasibility for classifying the ultrasound images of placenta with complicating diabetes by measuring the placenta thickness , area and biparietal diameter from the ultrasound placenta images. It is found that the thickness of placentae plays a major role in the classifying the ultrasound placenta images.

\section{FUTURE ENHANCEMENTS}

The future work focusses on the classification of placenta based on the principal component analysis.

\section{ACKNOWLEDGEMENTS}

Courtesy: Elvesier, Imaging Consult for providing the ultrasound images of placenta.

\section{REFERENCES}

[1] 'Diabetes is still poorly controlled in India': IDMPS study, www.pharmabiz.com/article/detnews, September 25,2009

[2] "Textbook of Diabetes and Pregnancy", Moshe Hod, Lois Jovanovi, Gian Carlo Di Renzo , Alberto De Leiva and Oded Langer

[3] "Effect of Gestational Diabetes and Maternal Hypertension on gross morphology of placenta", Muhammad Ashfaq, Muhammad Zahoor Janjua, Muhamman Aslam Channa, www.ayubmed.edi.pk/JAMC/PAST/17-1/Ashfaq.htm

[4] Arey LB. Developmental anatomy. $7^{\text {th }}$ ed; Philadelphia; WB Saunders 1974;131-6.

[5]. Kuhlmann RS, Warsof S. Ultrasound of the placenta. Clin Obstet Gynecol 1996.

[6] Fojaco RM, Hensley GT, Moskowitz L. Congenital syphilis and necrotizing funisitis. JAMA 1989;261: 178890.

[7] "Characterization of ultrasonic images of the placenta Based on textural features", P. A. Linares', P. J. Mccullagh', N. D. Black', J. Dornan', Proc of the 4th Annual IEEE Conf on Information Technology Applications in Biomedicine, UK

[8] "Wavelet Based Features For Ultrasound Placenta Images Classification", G. Malathi, Dr.V. Shanthi, $2^{\text {nd }}$ International Conference on Emerging Trends in Engineering and Technology, Nagpur, December 2009

[9] Feature selection for the characterization of ultrasonic images of the placenta using texture classification, P. A. Linares1, P. J. Mccullagh1, N. D. Black1, J. Dornan2, IEEE, 2004

[10] classification of ultrasonic images of placenta based on seeded region growing approach, G. Malathi, Dr.V. Shanthi, International Journal on Computer Engineering \& Information Technology, March-May 3009

[11] "Statistics on Placenta Shapes", Abhishek Bhattacharya, Conference on Current and Future Trends in NonParametrics, University of South Carolina, Columbia, October 2007 
[12] "Prediction of low birth weight infants from Ultrasound measurement of placental Diameter and placental thickness", F.A. Habib, Ann Saudi Med 2002

[13] "Placental thickness: A sonographic indicator of gestational age in normal singleton pregnancies in Nigerian women", Mr. Christopher Chukwuemeka Ohagwu, Dr. Paulinus Oshiotse Abu, Mr. Benjamin Effiong Udoh, Internet Journal of Medical Update, July2009

[14] "Relationship between placental thickness and growth parameters in normal Nigerian foetuses ", Ohagwu, C. C., Abu, P. O., Ezeokeke U.O., Ugwu, A .C., African Journal of Biotechnology, January, 2009 Courtesy: /www.academicjournals.org

[15] "Placental thickness in the first half of pregnancy", Theera Tongsong, Pongrak Boonyanurak, "Journal of Clinical Ultrasound", Volume 32 Issue 5, Pages 231 - 234 Published Online: 28 Apr 2004 , Courtesy: Wiley Periodicals, Inc.
[16] "Histogram Based Classification of Ultrasound Images of Placenta", G.Malathi, Dr.V.Shanthi, International Journal of Computer Applications, Feb 2010, Volume 1 - No. 16

\section{FIRST AUTHOR}

Mrs. G. Malathi, MCA., M.Phil., is working as a senior lecturer in the Department of Computer Applications in Velammal Engineering College. She is currently doing her $\mathrm{PhD}$ as part time in Mother Teresa Women's University, Kodaikanal. She has presented in 2 International and 4 National Conferences. Two Research paper has been published in an reputed International Journal.

\section{SECOND AUTHOR}

Dr. V. Shanthi, M.Sc., M.Phil., PhD is working as a Professor in the Department of Computer Applications in St. Joseph's Engineering College, Chennai affiliated to Anna University. She has published one book and published 7 research papers in National Journals and 8 in International Journals and 14 conferences . 